\title{
Relationship between physical and biogeochemical parameters and the scenario dependence of the transient climate response to cumulative carbon emissions
}

\author{
Kaoru Tachiiri
}

\begin{abstract}
The transient climate response to cumulative carbon emissions (TCRE) is a key metric in estimating the remaining carbon budget for given temperature targets. However, the TCRE has a small scenario dependence that can be non-negligible for stringent temperature targets. To investigate the parametric correlations and scenario dependence of the TCRE, the present study uses a 512-member ensemble of an Earth system model of intermediate complexity (EMIC) perturbing 11 physical and biogeochemical parameters under scenarios with steady increases of $0.25 \%, 0.5 \%, 1 \%, 2 \%$, or $4 \%$ per annum (ppa) in the atmospheric $\mathrm{CO}_{2}$ concentration $\left(\mathrm{pCO}_{2}\right)$, or an initial increase of $1 \%$ followed by an annual decrease of $1 \%$ thereafter. Although a small difference of $5 \%$ (on average) in the TCRE is observed between the 1-ppa and 0.5-ppa scenarios, a significant scenario dependence is found for the other scenarios, with a tendency toward large values in gradual or decline-after-a-peak scenarios and small values in rapidly increasing scenarios. For all scenarios, correlation analysis indicates a remarkably large correlation between the equilibrium climate sensitivity (ECS) and the relative change in the TCRE, which is attributed to the longer response time of the high ECS model. However, the correlations of the ECS with the TCRE and its scenario dependence for scenarios with large $\mathrm{pCO}_{2}$ increase rates are slightly smaller, and those of biogeochemical parameters such as plant respiration and the overall $\mathrm{pCO}_{2}$-carbon cycle feedback are larger, than in scenarios with gradual increases. The ratio of the TCREs under the overshooting (i.e., 1-ppa decrease after a 1-ppa increase) and 1ppa increase only scenarios had a clear positive relation with zero-emission commitments. Considering the scenario dependence of the TCRE, the remaining carbon budget for the $1.5^{\circ} \mathrm{C}$ target could be reduced by 17 or $22 \%$ (before and after considering the unrepresented Earth system feedback) for the most extreme case (i.e., the $67^{\text {th }}$ percentile when using the 0.25-ppa scenario as compared to the 1-ppa increase scenario). A single ensemble EMIC is also used to indicate that, at least for high ECS (high percentile) cases, the scenario dependence of the TCRE should be considered when estimating the remaining carbon budget.
\end{abstract}

Keywords: Transient climate response to cumulative carbon emissions, Scenario dependence, Earth system models of intermediate complexity, Equilibrium climate sensitivity, Zero-emission commitment, Carbon budget

\footnotetext{
Correspondence: tachiiri@jamstec.go.jp

Research Center for Environmental Modeling and Application, Research Institute for Global Change, Japan Agency for Marine-Earth Science and Technology, 3173-25 Showamachi, Kanazawaku, Yokohama, Kanagawa 236-0001, Japan
} 


\section{Introduction}

Although a large inter-model uncertainty remains, discussions on future carbon emission pathways are assisted by the observation that the transient climate response to cumulative carbon emissions (TCRE) is largely unaffected by time and pathways (e.g., Collins et al. 2013). For example, in searching for pathways to maintain a given temperature target, one can first estimate the total allowable carbon emissions and then consider how to distribute the emissions for each year.

According to Rogelj et al. (2019), the remaining carbon budget $\left(B_{\text {lim }}\right)$ can be calculated from the TCRE using Eq. (1):

$$
B_{\text {lim }}=\left(T_{\text {lim }-} T_{\text {hist }}-T_{\text {nonCO2 }}-T_{\mathrm{ZEC}}\right) / \mathrm{TCRE}-E_{\text {esfb }}
$$

where $T_{\text {lim }}, T_{\text {hist }}, T_{\text {nonCO2 }}$, and $T_{\mathrm{ZEC}}$ are the temperature change limit, the historical human-induced warming to-date, the non- $\mathrm{CO}_{2}$ contributions to a future temperature increase, and the zero-emissions commitment (ZEC), respectively, and $E_{\text {esfb }}$ is an adjustment term for sources of unrepresented Earth system feedback.

In the Special Report on Global Warming of $1.5^{\circ} \mathrm{C}$ by the Intergovernmental Panel on Climate Change (IPCC) (SR1.5; Rogelj et al. 2018), experts calculated the remaining carbon budget from Eq. (1) using TCRE values that were estimated in the IPCC AR5 (i.e., 0.8-2.5 $\mathrm{K} / \mathrm{GtC}$; Collins et al. 2013). Although this estimate was the result of expert judgment based on various existing studies using stabilizing, overshooting, and increasing scenarios, the TCRE range of $0.8-2.4 \mathrm{~K} / \mathrm{GtC}$ estimated by Gillet et al. (2013) using Earth systems models (ESMs) seems remarkably influential. In addition, Gillet et al. (2013) used a scenario with a monotonic increase of $1 \%$ per annum (ppa) in the atmospheric $\mathrm{CO}_{2}$ concentration $\left(\mathrm{pCO}_{2}\right)$. This corresponding to the threshold exceedance budgets (TEBs), or total carbon emissions of the underlying scenarios up to the time of exceeding the threshold, as defined by Rogelj et al. (2016). In other words, only transient warming is considered. The remaining carbon budget is more closely related to another type of budget, which was termed the threshold avoidance budget (TAB) by Rogelj et al. (2016) for the non-overshooting case, and which reflects the total carbon emissions of the underlying scenarios up to the time of peak warming (i.e., slow warming is also considered). For the average value, however, the results of the Zero Emissions Commitment Model Inter-comparison Project (ZEC-MIP; MacDougall et al. 2020) indicated that warming after the cessation of $\mathrm{CO}_{2}$ emissions (i.e., the ZEC) can be approximately estimated as zero $\left(T_{\mathrm{ZEC}}=0\right)$.
In that case, the $\mathrm{TAB}$ can be considered to be equal to the TEB.

Tachiiri et al. (2015) demonstrated that the uncertainty of the TCRE increases (i.e., large TCREs get larger and small TCREs get smaller) when the $\mathrm{pCO}_{2}$ is stabilized, although the average (or median) TCRE remains unchanged. Hence, the TABs can be smaller than the TEB if we need to achieve the target with a high probability, whereas the TABs and TEBs are expected to be similar when considering approximately the $50^{\text {th }}$ percentile.

Although the initial main focus of researchers was the quasi-constancy of the TCRE, the scenario dependence of the TCRE has been previously reported (Hajima et al. 2012; Krasting et al. 2014). More recently, MacDougall (2017) concluded that the TCRE is only nearly constant (i.e., $<5 \%$ change) when changes in the $\mathrm{pCO}_{2}$ are $0.3-$ $1.2 \%$ p.a. at $400 \mathrm{ppm}$ (or $0.5-2.5 \%$ p.a. at $>1000 \mathrm{ppm}$ ). For overshooting scenarios, Zickfeld et al. (2016) indicated some increase in the TCRE and Tachiiri et al. (2019) quantified a 10-20\% increase in the TCRE under a decline-after-a-peak $\mathrm{pCO}_{2}$ (i.e., declining part of an overshooting) scenario. By contrast, MIROC-ES2L (Hajima et al. 2020), which is the new model in the MIROC-ESM series, has shown a non-increase in the TCRE in the decline part of an overshooting scenario (Hajima, personal communication). Thus, whether the TCRE increases in the declining part of overshooting scenarios (i.e., the existence of a scenario dependence) depends on the model. While the quasi-constancy of the TCRE is obviously interesting and helpful, TCRE changes, which have not been the focus thus far, could be important when estimating the remaining carbon budget. Therefore, investigating the magnitude of scenario dependence, and identifying those cases in which the scenario dependence is enhanced, can be important for estimating the remaining carbon budget for given temperature targets.

The present study aims to (1) confirm the magnitude of the scenario dependence of the TCRE and (2) investigate in which cases the TCRE has a high (or low) scenario dependence. To achieve these aims, a single model ensemble perturbing physical and biogeochemical parameters using an Earth system model of intermediate complexity (EMIC) is conducted to investigate the magnitude of the scenario dependence of the TCRE and its correlations with each parameter. In addition, the mechanism of scenario dependence and its impact on the estimation of the remaining carbon budget are discussed.

\section{Methods}

The present study uses the MIROC-lite/JUMP-LCM (Tachiiri et al. 2010, 2013) model, which contains a fully coupled core general ocean circulation model, with a 
biogeochemical nutrition-phytoplankton-zooplanktondetritus (NPZD) component, and an energy moisture balance atmosphere model (Oka et al. 2011). In addition, MIROC-lite uses a simple, one-layer-bucket land model to close the water budget by considering precipitation (snow and rain), snowmelt, evaporation, and runoff. However, the spatial distribution of climatic variables is insufficiently represented by this model-especially precipitation, which is difficult to represent with a twodimensional atmosphere model. This was compensated for when calculating the land carbon uptake by using the loosely coupled Sim-CYCLE model, a process-based land ecosystem model that includes vegetation and soil (Ito and Oikawa 2002) in combination with once-yearly data interactions with the global mean surface air temperature (GMSAT). First, the annual mean GMSAT for the year in question was calculated from the output of MIROC-lite. In addition, a dataset was prepared from the output of the 1-ppa scenario using the mediumresolution version of MIROC3.2 (K-1 model developers 2004). The annual mean GMSAT data for the year in question were then examined, and the most similar datum to that of the MIROC-lite output was called from the prepared MIROC3.2 dataset. This information was then input to Sim-CYCLE. The variables called to run the vegetation model were cloud cover, precipitation, specific humidity, shortwave radiation, air temperature, and soil temperature at depths of $10 \mathrm{~cm}$ and $200 \mathrm{~cm}$. This combined model has been employed in international model inter-comparison projects such as
EMIC-AR5 (Weaver et al. 2012; Eby et al. 2013; Zickfeld et al. 2013) and ZEC-MIP (MacDougall et al. 2020).

For the model, 512 parameter sets were developed by using the Latin hypercube method to perturb the 11 parameters listed in Table 1 (i.e., parameter sets were generated with equal distribution in the 11-dimension parameter space). These parameters include the GentMcWilliams thickness parameter that measures the eddy-induced velocity of the ocean (Gent and McWilliams 1990). In addition, a freshwater flux adjustment is necessary in order to realistically represent the meridional overturning circulation. For measuring the marine carbon cycle response, changing the photosynthesis parameters proved ineffective at varying the carbon cycle sensitivity to $\mathrm{pCO}_{2}$ and temperature. Therefore, an atmosphere-ocean gas exchange coefficient was implemented as a perturbation parameter.

The ranges of the parameters perturbed were selected on the basis of the original ranges given in Table $\mathrm{B} 1$ of Tachiiri et al. (2013) rather than the final range in Table 1 of the same work. Whereas Tachiiri et al. (2013) considered the representability of the Coupled Climate Carbon Cycle Model Inter-comparison Project (C4MIP) models (Friedlingstein et al. 2006), the ranges of parameter perturbation in the present work are based on previous studies. In particular, the range of horizontal diffusivity is determined on the basis of Collins et al. (2007) and Roach et al. (2018), and is significantly narrowed. The reasons for the varying ranges of the parameters are given in more detail in the Supplementary

Table 1 Nature and ranges of the parameters perturbed in the present study

\begin{tabular}{|c|c|c|c|c|c|}
\hline Parameter & Component & Default & Range & $\begin{array}{l}\text { High weight } \\
\text { range }\end{array}$ & Ref. \\
\hline Climate sensitivity & Atmosphere & 1.7 & $1-6 \mathrm{~K}$ & $2-4.5 \mathrm{~K}$ & a \\
\hline Vertical diffusivity & Ocean & $0.1-2.5 \mathrm{~cm}^{2} / \mathrm{s}^{*}$ & $0.5-2.0 \times$ default & - & $b-g$ \\
\hline Horizontal diffusivity & Ocean & $1 \times 10^{7} \mathrm{~cm}^{2} / \mathrm{s}$ & $0.35-1.5 \times$ default & - & $h, i$ \\
\hline Gent-McWilliams thickness & Ocean & $7 \times 10^{6} \mathrm{~cm}^{2} / \mathrm{s}$ & $1-10 \times 10^{6} \mathrm{~cm}^{2} \mathrm{~s}^{-1}$ & - & $J$ \\
\hline Magnitude of freshwater flux adjustment & Ocean & $\begin{array}{l}1.0 \text { (ratio to the } \\
\text { values by Oort 1983) }\end{array}$ & $0.5-2.0$ & - & k \\
\hline Coefficient for marine $\mathrm{CO}_{2}$ uptake & Marine carbon & 1 & $0.4-1.0$ & - & $\begin{array}{l}\mathrm{l}, \mathrm{m} \\
\mathrm{n}\end{array}$ \\
\hline Maximum photosynthetic rate & Land carbon & $8.0-13.5 \mu \mathrm{molCO}_{2} /\left(\mathrm{m}^{2} \mathrm{~s}\right)^{* *}$ & $0.8-3.0 \times$ default & $0.8-2.0 \times$ default & O \\
\hline Specific leaf area & Land carbon & ${ }_{* *}^{110-170 \mathrm{~cm}^{2} /(\mathrm{g} \text { dry matter })}$ & $0.5-2.5 \times$ default & $0.5-1.5 \times$ default & $p, q$ \\
\hline Minimum temperature for photosynthesis & Land carbon & $-5.0-11.0^{\circ} \mathrm{C} * *$ & $\begin{array}{l}-3.0-+3.0{ }^{\circ} \mathrm{C} \\
\text { of default }\end{array}$ & - & r \\
\hline $\begin{array}{l}\text { Coefficient for temperature dependency of plant } \\
\text { respiration }\end{array}$ & Land carbon & 2.0 (dimensionless) & $1.5-3.0$ & - & $s, t$ \\
\hline $\begin{array}{l}\text { Parameter of temperature dependency of soil } \\
\text { respiration }\end{array}$ & Land carbon & $46.02 \mathrm{~K}$ & $40-60 \mathrm{~K}$ & - & r \\
\hline
\end{tabular}

* Depth-dependent; **biome-dependent; a: Bindoff et al. (2013); b: Huber and Zanna (2017); c: Hasumi and Suginohara (1999); d: Tatebe et al. (2018); e: Melet et al. (2016); f: Simmons et al. (2004); g: Waterhouse et al. (2014); h: Collins et al. (2007); i: Roach et al. (2018); j: Visbeck et al. (1997); k: Talley (2008); I: Denman et al. (2007); m: Ciais et al. (2013); n: Tachiiri et al. (2013); o: Peterson et al. (1999); p: Kattge et al. (2011); q: Gong and Gao (2019); r: Verbeeck et al. (2011); s: Bolstad et al. (1999); t: Tjoelker et al. (2001) 
Information (SI_201015_1126.docx). In addition, while a temporally unchanged but spatially varying wind speed (namely, the average value from the ERA5 reanalysis for 1979-2020 (Copernicus Climate Change Service 2017)) is used to calculate marine ocean uptake, the coefficient of aerosol forcing is not applicable here since the scenarios only consider the $\mathrm{pCO}_{2}$ change.

As indicated in Fig. 1 and Table 2, the following concentration pathways were applied to the study scenarios:

(a) $I-1 \%: 1$ ppa increase to $2 \times \mathrm{CO}_{2}$ (dark blue line)

(b) $I-0.5 \%: 0.5 \mathrm{ppa}$ increase to $2 \times \mathrm{CO}_{2}$ (green line)

(c) $I-0.25 \%: 0.25$ ppa to $2 \times \mathrm{CO}_{2}$ (red line)

(d) $I-2 \%: 2$ ppa to $2 \times \mathrm{CO}_{2}$ (light blue line)

(e) I-4\%: 4 ppa for 40 years, up to around $4.5 \times \mathrm{CO}_{2}$ (purple line)

(f) D-1\%: 1 ppa decrease from $2 \times \mathrm{CO}_{2}$ after (a) (black line)

In addition, a biogeochemically coupled run was performed for the $I-1 \%$ scenario and a zero-emission experiment was initiated from the end of the $I-1 \%$ scenario.

Before the experiments, as spin-up, all members of the atmosphere-ocean and land ecosystem parts were run for 3000 and 2000 years, respectively. The TCRE for each scenario was the average for years $21-280$ for the $I-0.25 \%$ scenario, $21-140$ for the $I-0.5 \%$ scenario, $21-70$ for the $I-1 \%$ scenario, $21-40$ for the $I-2 \%$ scenario, $15-$ 24 for the $I-4 \%$ scenario, and $1-50$ for the $D-1 \%$ scenario. Years $1-20$ and the final 20 years of the $D-1 \%$ scenario were removed to avoid the instability caused by very small cumulative carbon emissions. The average of the 10 -year period for the $I-4 \%$ scenario was centered on year 19, where the $\mathrm{CO}_{2}$ concentration level was doubled. Note that the TCRE for the $D-1 \%$ scenario was calculated from the temperature anomaly and cumulative

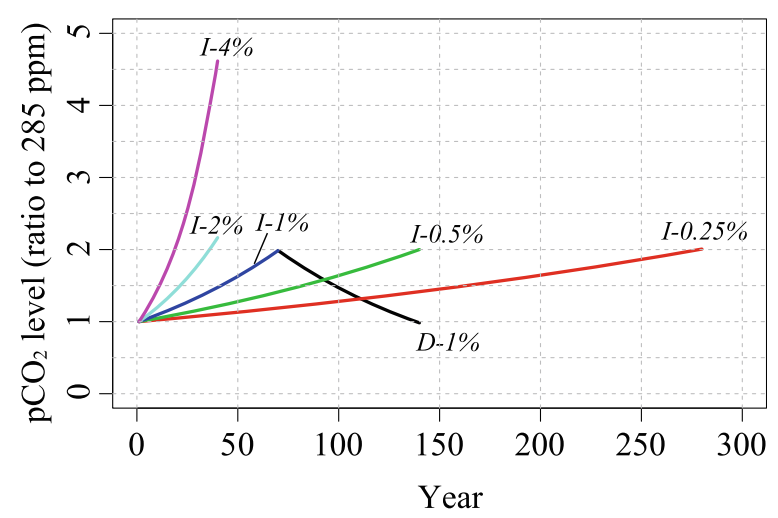

Fig. 1 Plots of $\mathrm{pCO}_{2}$ levels against time (years) for the various study scenarios: I-1\% (dark blue line); I-0.5\% (green line); I-0.25\% (red line); I2\% (light blue line); I-4\% (Purple line); D-1\% (black line) carbon emissions at the start of the precedent $I-1 \%$ scenario so a combination of $I-1 \%$ and $D-1 \%$ could provide an example of an overshooting scenario.

To investigate the correlation between the $\mathrm{CO}_{2}$-carbon cycle and climate-carbon cycle feedback to the TCRE and its scenario dependence, a biogeochemically coupled run of the $I-1 \%$ scenario was performed in which ecosystems were subject to an increasing $\mathrm{pCO}_{2}$ but the $\mathrm{CO}_{2}$ did not function as a greenhouse gas. The TCRE can be decomposed to Eq. (2):

$$
\alpha /(1+\beta+\alpha \gamma)
$$

where $\alpha[\mathrm{K} / \mathrm{GtC}], \beta[\mathrm{GtC} / \mathrm{GtC}]$, and $\gamma[\mathrm{GtC} / \mathrm{K}]$ are the linear transient climate sensitivity to $\mathrm{pCO}_{2}$ increase, the $\mathrm{CO}_{2}$-carbon cycle feedback, and the climate-carbon cycle feedback, respectively (Friedlingstein et al. 2006; Gregory et al. 2009). Hence, these are assumed to directly influence the change in the TCRE. Here, in calculating $\beta$ and $\gamma$, the effects of temperature change on the biogeochemically coupled run is confirmed to be small, and $\beta$ and $\gamma$ are simply calculated using Eqs. (3) and (4) (Arora et al. 2020):

$$
\begin{aligned}
& \beta=\frac{\Delta C_{b}}{\Delta C A} \\
& \gamma=\frac{\Delta C_{f}-\Delta C_{b}}{\Delta T_{f}}
\end{aligned}
$$

where $\Delta \mathrm{C}_{\mathrm{b}}$ and $\Delta \mathrm{C}_{\mathrm{f}}$ are the total change in land and ocean carbon storage in the biogeochemically and fully coupled runs, respectively; $\triangle \mathrm{CA}$ is the change in the atmospheric carbon, and $\Delta \mathrm{T}_{\mathrm{f}}$ is the temperature change in the fully coupled run. Here, values for the $70^{\text {th }}$ year were used.

To examine the relationship between the scenario dependence of the TCRE and the ZEC, a ZEC experiment was performed. In contrast to ZEC-MIP (MacDougall et al. 2020), which starts the zero-emission period when the cumulative emissions reach their given levels (i.e., 750,1000 , and $2000 \mathrm{GtC}$ ), the start of the zero-emission period in the present study is the $70^{\text {th }}$ year of the $I-1 \%$ scenario. Moreover, the ZEC values up to the temperature peak (the same as Eq. (1)), the $25^{\text {th }}$ (the average of the $20^{\text {th }}-29^{\text {th }}$ ), and the $50^{\text {th }}$ (the average of the $\left.45^{\text {th }}-54^{\text {th }}\right)$ years are used for the analysis, whereas ZEC-MIP uses the averages of 10 years centering on the $25^{\text {th }}, 50^{\text {th }}$, and $90^{\text {th }}$.

For three parameters, namely the equilibrium climate sensitivity (ECS), the maximum photosynthetic rate, and the specific leaf area, values near the edges of the ranges are given smaller weights, as shown in Figure S1. Thus, for the ECS, the weight linearly increases from 0 to 1 as the ECS increases from 1 to 2; the weight then remains at 1 throughout the $2-4.5 \mathrm{~K}$ range before linearly 
Table 2 Study scenarios

\begin{tabular}{lllll}
\hline Scenario & $\boldsymbol{p} \mathbf{C O}_{2}$ change rate & Start $\mathbf{C O}_{2}$ level & End $\mathbf{C O}_{2}$ level & Duration (years) \\
\hline $1-1 \%$ & $1 \%$ p.a. increase & $1 \times \mathrm{CO}_{2}$ (Initial) & $2 \times \mathrm{CO}_{2}$ & 70 \\
$1-0.25 \%$ & $0.25 \%$ p.a. increase & $1 \times \mathrm{CO}_{2}$ (Initial) & $2 \times \mathrm{CO}_{2}$ & 280 \\
$1-0.5 \%$ & $0.5 \%$ p.a. increase & $1 \times \mathrm{CO}_{2}$ (Initial) & $2 \times \mathrm{CO}_{2}$ & 140 \\
$1-2 \%$ & $2 \%$ p.a. increase & $1 \times \mathrm{CO}_{2}$ (Initial) & $2 \times \mathrm{CO}_{2}$ & 40 \\
$1-4 \%$ & $4 \%$ p.a. increase & $1 \times \mathrm{CO}_{2}$ (Initial) & $4.5 \times \mathrm{CO}_{2}$ & 40 \\
- $1 \%$ & $1 \%$ p.a. decrease & $2 \times \mathrm{CO}_{2}$ (after $\left.11.0 \%\right)$ & $1 \times \mathrm{CO}_{2}$ & 70 \\
\hline
\end{tabular}

decreasing to 0 beyond that range (Figure S1a). The coefficient of maximum photosynthetic rates of between 2 and 3 have smaller weights (Figure S1b), and specific leaf areas of between 1.5 and 2.5 have smaller weights (Figure S1c). The total weight is calculated as the product of the weights for these three parameters. For the members which develop negative cumulative carbon emissions during the experiments (as happens for two members in the $D-1 \%$ scenario), the end of the period for calculating the average TCRE is moved to 20 years prior to the year in which the TCRE becomes negative.

\section{Results and discussion}

\subsection{Scenario dependence of the TCRE}

The distribution in the TCRE change for each scenario relative to that of the $I-1 \%$ scenario is presented in Fig. 2. Here, many members under the $I-0.5 \%$ scenario (green line) have similar (slightly larger) TCRE values than those under the $I-1 \%$ scenario; the average ratio of the TCRE to that of $I-1 \%$ is 1.05 , the peak is in the $1.0-1.1 \mathrm{bin}$, and $50 \%$ of the members are within the range of $\pm 5 \%$ difference from those of the $I-1 \%$ scenario. Under the $I-2 \%$ scenario (light blue line), the distribution is shifted toward small TCREs with a peak in the $0.9-1.0$ bin; the average is

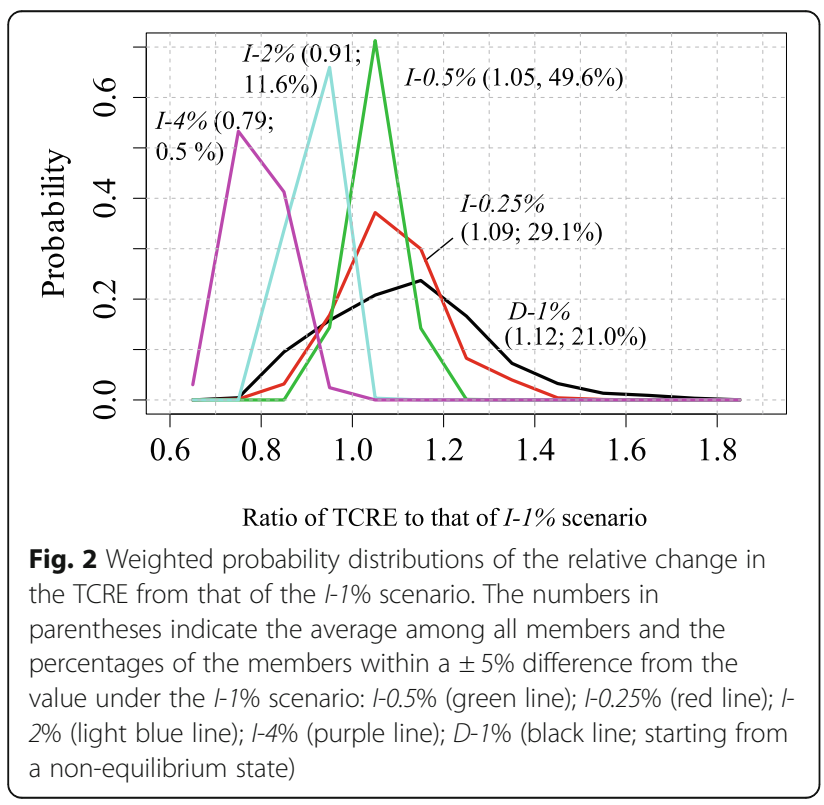

0.91 , and $12 \%$ are within the range of $\pm 5 \%$ difference from those under the $I-1 \%$ scenario. The other peaks occur at $0.7-0.8,1.0-1.1$, and $1.1-1.2$ for the $I-4 \%$ (purple line), $I$ $0.25 \%$ (red line), and $D-1 \%$ (black line) scenarios, respectively, with corresponding averages of $0.79,1.09$, and 1.12 . The corresponding fractions of members within the range of $\pm 5 \%$ difference from the $I-1 \%$ scenario are $0.5 \%, 29 \%$, and $21 \%$, respectively. These results clearly indicate that the TCRE tends to increase under scenarios with a slowly increasing $\mathrm{pCO}_{2}$ and decrease under scenarios with a rapidly increasing $\mathrm{pCO}_{2}$. In the case of $D-1 \%$, with a 1 -ppa decease from the non-equilibrium $2 \times \mathrm{CO}_{2}$ level, the TCRE is even larger than that of the $I-0.25 \%$ scenario. The large similarity between $I-1 \%$ and $I-0.5 \%$ is consistent with the results of MacDougall (2017), who concluded that the TCRE is only close to constant (i.e., $<5 \%$ change) at a $\mathrm{pCO}_{2}$ of $0.3-1.2 \%$ p.a. at 400 ppm.

\subsection{Correlations of the parameters to the scenario dependence of the TCRE}

The coefficients of correlation between each parameter and the TCRE for the $I-1 \%$ scenario are presented in Table 3. Also shown are the correlations between each parameter and ratio of the TCRE value of each alternative scenario to that of the $I-1 \%$ scenario. Unsurprisingly, the correlations of many parameters display opposite signs depending on whether the specific scenario has a larger or smaller rate of increase in the $\mathrm{pCO}_{2}$ relative to that of the $I-1 \%$ scenario. This is a direct result of using the ratio of the specific scenario TCRE to that of the $I$ $1 \%$ scenario as the metric.

An examination of Table 3 indicates that the ECS parameter is especially strongly correlated to the TCRE value of the $I-1 \%$ scenario and to the ratio of the TCRE values of all other scenarios to that of the $I-1 \%$ scenario. Among the other parameters, relatively large correlations with the scenario dependence of the TCRE are observed for the plant respiration parameter, the coefficient for marine carbon uptake, the maximum photosynthetic rate, and the specific leaf area, particularly for rapid $\mathrm{pCO}_{2}$ increase scenarios. Among the physical parameters, the vertical diffusivity of the ocean displays a significant correlation. For the $D-1 \%$ scenario, the maximum photosynthetic rate and plant respiration 
Table 3 Correlation between each parameter, and TCRE in the $1-1 \%$ scenario and the relative TCRE change from the $1-1 \%$ scenario

\begin{tabular}{|c|c|c|c|c|c|c|}
\hline Parameter & $I-1 \%$ & $D-1 \%$ & $1-0.25 \%$ & $1-0.5 \%$ & $I-2 \%$ & $I-4 \%$ \\
\hline Equilibrium climate sensitivity (ECS) & $\begin{array}{l}0.829 \\
0.835^{* * *}\end{array}$ & $\begin{array}{l}0.865 \\
0.891^{* * *}\end{array}$ & $\begin{array}{l}0.762 \\
0.791^{* * *}\end{array}$ & $\begin{array}{l}0.775 \\
0.785^{* * *}\end{array}$ & $\begin{array}{l}-0.742 \\
-0.743^{* * *}\end{array}$ & $\begin{array}{l}-0.776 \\
-0.773^{* * *}\end{array}$ \\
\hline Vertical diffusivity & $\begin{array}{l}-0.199 \\
-0.191^{* * *}\end{array}$ & $\begin{array}{l}-0.144 \\
-0.135^{* * *}\end{array}$ & $\begin{array}{l}-0.084 \\
-0.079\end{array}$ & $\begin{array}{l}-0.140 \\
-0.129^{* *}\end{array}$ & $\begin{array}{l}0.176 \\
0.172^{* *}\end{array}$ & $\begin{array}{l}0.193 \\
0.192^{* * *}\end{array}$ \\
\hline Horizontal diffusivity & $\begin{array}{l}0.035 \\
0.047\end{array}$ & $\begin{array}{l}0.080 \\
0.076\end{array}$ & $\begin{array}{l}0.091 \\
0.082\end{array}$ & $\begin{array}{l}0.090 \\
0.085\end{array}$ & $\begin{array}{l}-0.050 \\
-0.060\end{array}$ & $\begin{array}{l}-0.043 \\
-0.051\end{array}$ \\
\hline Gent-McWilliams thickness & $\begin{array}{l}0.066 \\
0.072\end{array}$ & $\begin{array}{l}0.000 \\
0.007\end{array}$ & $\begin{array}{l}-0.009 \\
-0.008\end{array}$ & $\begin{array}{l}-0.005 \\
-0.008\end{array}$ & $\begin{array}{l}-0.018 \\
-0.025\end{array}$ & $\begin{array}{l}-0.004 \\
-0.006\end{array}$ \\
\hline Freshwater flux adjustment & $\begin{array}{l}-0.024 \\
-0.019\end{array}$ & $\begin{array}{l}0.020 \\
0.031\end{array}$ & $\begin{array}{l}0.010 \\
0.016\end{array}$ & $\begin{array}{l}0.004 \\
0.007\end{array}$ & $\begin{array}{l}0.023 \\
0.023\end{array}$ & $\begin{array}{l}0.022 \\
0.019\end{array}$ \\
\hline Marine CO2 uptake & $\begin{array}{l}-0.294 \\
-0.288^{* * *}\end{array}$ & $\begin{array}{l}0.018 \\
0.038\end{array}$ & $\begin{array}{l}-0.110 \\
-0.097\end{array}$ & $\begin{array}{l}-0.091 \\
-0.092\end{array}$ & $\begin{array}{l}0.152 \\
0.160^{* *}\end{array}$ & $\begin{array}{l}0.164 \\
0.178^{* * *}\end{array}$ \\
\hline Maximum photosynthetic rate & $\begin{array}{l}0.026 \\
0.046\end{array}$ & $\begin{array}{l}0.239 \\
0.207^{* * *}\end{array}$ & $\begin{array}{l}0.113 \\
0.089\end{array}$ & $\begin{array}{l}0.109 \\
0.094\end{array}$ & $\begin{array}{l}-0.127 \\
-0.135^{* * *}\end{array}$ & $\begin{array}{l}-0.131 \\
-0.154^{* * *}\end{array}$ \\
\hline Specific leaf area & $\begin{array}{l}-0.205 \\
-0.186^{* * *}\end{array}$ & $\begin{array}{l}0.072 \\
0.045\end{array}$ & $\begin{array}{l}-0.114 \\
-0.121^{*}\end{array}$ & $\begin{array}{l}-0.138 \\
-0.139^{* *}\end{array}$ & $\begin{array}{l}0.184 \\
0.170^{* *}\end{array}$ & $\begin{array}{l}0.173 \\
0.153^{* *}\end{array}$ \\
\hline Minimum temperature for photosynthesis & $\begin{array}{l}-0.032 \\
-0.036\end{array}$ & $\begin{array}{l}-0.026 \\
-0.018\end{array}$ & $\begin{array}{l}-0.097 \\
-0.092\end{array}$ & $\begin{array}{l}-0.083 \\
-0.081\end{array}$ & $\begin{array}{l}0.084 \\
0.086\end{array}$ & $\begin{array}{l}0.057 \\
0.066\end{array}$ \\
\hline Temperature dependency of plant respiration & $\begin{array}{l}0.233 \\
0.235^{* * *}\end{array}$ & $\begin{array}{l}0.219 \\
0.213^{* * *}\end{array}$ & $\begin{array}{l}0.347 \\
0.349^{* * *}\end{array}$ & $\begin{array}{l}0.367 \\
0.371^{* * *}\end{array}$ & $\begin{array}{l}-0.393 \\
-0.399^{* * *}\end{array}$ & $\begin{array}{l}-0.364 \\
-0.376^{* * *}\end{array}$ \\
\hline Temperature dependency of soil respiration & $\begin{array}{l}-0.032 \\
-0.031\end{array}$ & $\begin{array}{l}-0.047 \\
-0.025\end{array}$ & $\begin{array}{l}-0.008 \\
0.002\end{array}$ & $\begin{array}{l}-0.028 \\
0.030\end{array}$ & $\begin{array}{l}-0.066 \\
-0.049\end{array}$ & $\begin{array}{l}-0.040 \\
-0.018\end{array}$ \\
\hline CO2-carbon cycle feedback ( $\beta$ ) & $\begin{array}{l}-0.346 \\
-0.324^{* * *}\end{array}$ & $\begin{array}{l}-0.040 \\
-0.047\end{array}$ & $\begin{array}{l}-0.239 \\
-0.261^{* * *}\end{array}$ & $\begin{array}{l}-0.306 \\
-0.313^{* * *}\end{array}$ & $\begin{array}{l}0.386 \\
0.379^{* * *}\end{array}$ & $\begin{array}{l}0.354 \\
0.339^{* * *}\end{array}$ \\
\hline Climate-carbon cycle feedback $(y)$ & $\begin{array}{l}0.053 \\
0.014\end{array}$ & $\begin{array}{l}0.001 \\
0.029\end{array}$ & $\begin{array}{l}-0.026 \\
0.033\end{array}$ & $\begin{array}{l}0.064 \\
0.050\end{array}$ & $\begin{array}{l}0.039 \\
0.002\end{array}$ & $\begin{array}{l}0.031 \\
0.026\end{array}$ \\
\hline TCRE of $1-1 \%$ & - & $\begin{array}{l}0.810 \\
0.835^{* * *}\end{array}$ & $\begin{array}{l}0.831 \\
0.863^{* * *}\end{array}$ & $\begin{array}{l}0.869 \\
0.885^{* * *}\end{array}$ & $\begin{array}{l}-0.922 \\
-0.928^{* * *}\end{array}$ & $\begin{array}{l}-0.943 \\
-0.949^{* * *}\end{array}$ \\
\hline
\end{tabular}

In each cell, the upper and lower lines show the weighted Pearson's product-moment correlation and the weighted Spearman's rank correlation, respectively (weights are considered in calculating the variance and co-variance for the independent and dependent variables). For the latter, ${ }^{*}{ }^{* *}$, and ${ }^{* * *}$ indicate statistical significance at the $10 \%, 5 \%$, and $1 \%$ levels, respectively (the sum of the weights for all members, i.e., 222.17 , is used as the sample size in the statistical significance test)

parameter display relatively large correlations with the scenario dependence of the TCRE.

For comprehensive sensitivities, the $\mathrm{CO}_{2}$-carbon cycle feedback $(\beta)$ is fairly strongly correlated with the TCRE under the $I-1 \%$ scenario and is relatively unchanged under all other scenarios except for the $D-1 \%$ scenario. The climate-carbon cycle feedback $(\gamma)$ displays a weak correlation to the TCRE and its scenario dependence, although the unweighted case shows a statistically significant correlation in slow $\mathrm{pCO}_{2}$ increase scenarios (not shown). For fast $\mathrm{pCO}_{2}$ increase scenarios, the correlation of the ECS is slightly reduced and $\beta$ instead displays a slightly larger correlation relative to that in slow scenarios. When the TCRE is large under the $I-1 \%$ scenario, the TCRE is seen to increase under slower scenarios $(D$ $1 \%, I-0.25 \%$, and $I-0.5 \%)$ and to decrease under faster scenarios $(I-2 \%$ and $I-4 \%)$, with very large absolute coefficients of correlation (0.81-0.94 and 0.84-0.95 for Pearson's and Spearman's coefficients, respectively).

The correlation between the ECS and the TCRE under the $I-1 \%$ scenario, and between the ECS and the ratio of the TCRE value of each alternative scenario to that of the $I-1 \%$ scenario, are indicated by the scatter plots in Fig. 3. The TCRE is seen to be almost independent of scenarios that are slower than the $I-1 \%$ scenario for models with an ECS of 2-3 K (i.e., the ratio of the TCRE to that of the $I-1 \%$ scenario was is close to 1 ) and has a value of approximately $1.5-1.6 \mathrm{~K} / 1000 \mathrm{GtC}$ (see also Figure $\mathrm{S} 2 \mathrm{a}$, which shows that the deviation from the $I$ $1 \%$ scenario is smallest for an ECS of $2-3 \mathrm{~K}$ under slow scenarios). For the $I-2 \%$ and $I-4 \%$ scenarios, a smaller ECS results in a lesser scenario dependence. The ECS correlation is seen to decrease under fast scenarios, and this is attributed to the relatively small variation in the temperature anomaly among the members in rapid scenarios, particularly when the ECS is high (Fig. 3e, f).

The ECS dependences of the temperature and cumulative carbon emissions for the various scenarios are presented in Figure S3a-d. The large correlation between the ECS and the TCRE change results from the combined influence of temperature and cumulative carbon emissions. High ECS models have previously been 


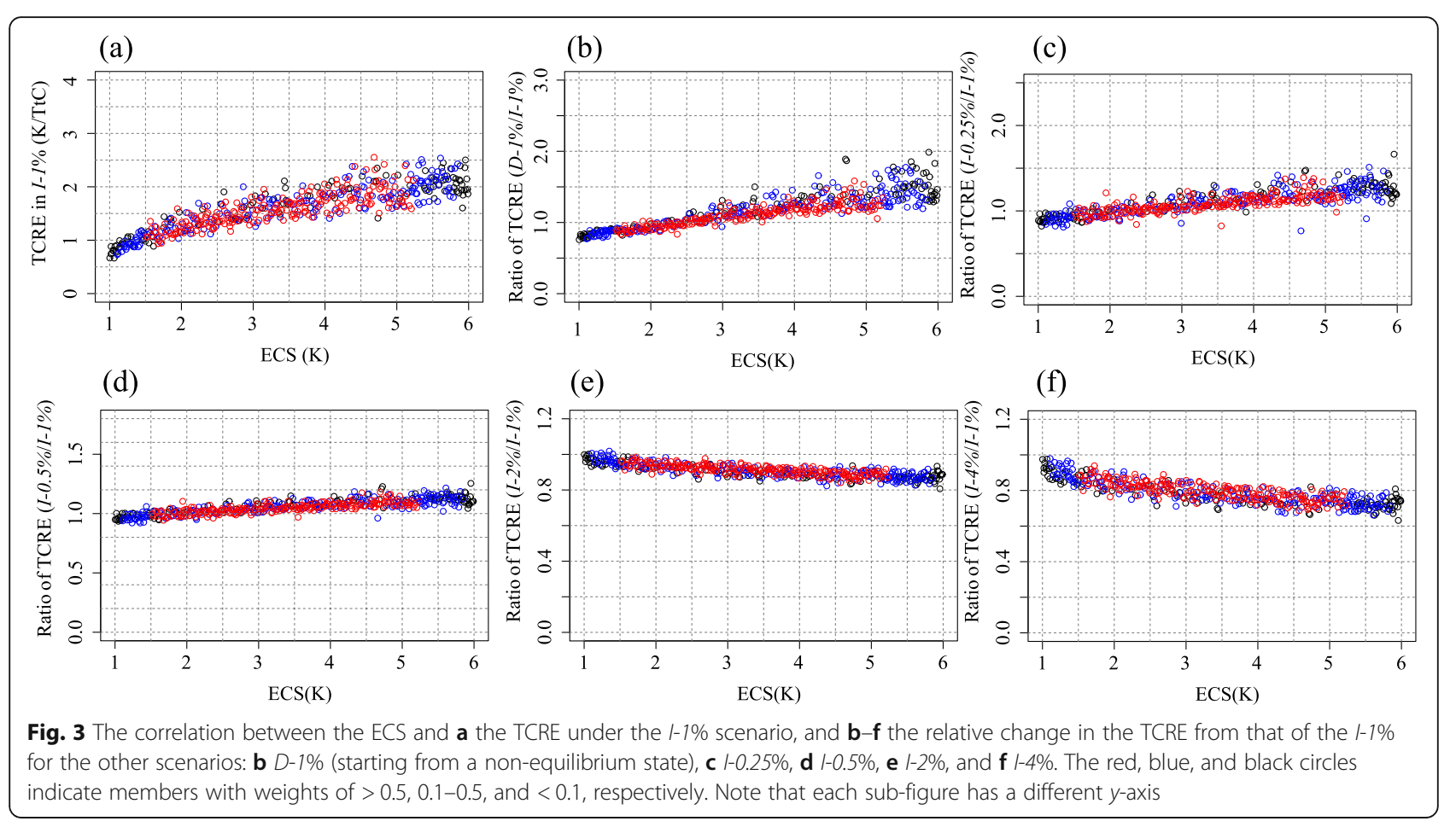

shown to have low transient climate responses (TCRs) to the ECS ratio (Millar et al. 2015, Tsutsui 2017, 2020); i.e., these models are prone to longer responses. This tendency is confirmed in the present study (Figure S3f). Thus, members of high ECS respond more slowly than members of low ECS, generating a smaller temperature rise for a given level of emission (smaller TCRE) in fast $\mathrm{pCO}_{2}$ increase scenarios than in slow $\mathrm{pCO}_{2}$ increase scenarios. This higher realized fraction (i.e., ratio to the value when the system is equilibrated for a given $\mathrm{pCO}_{2}$ condition) for warming in slow scenarios becomes even more remarkable in the declining part of overshooting scenarios (Fig S3c); in overshooting, the system is warmed up when it experiences a high $\mathrm{pCO}_{2}$ condition, causing high realized warming fraction in the following period. Actually, a similar effect occurs for $\mathrm{CO}_{2}$ too (Fig S3d), but as the temperature is more sensitive, the TCRE rise in the declining part of the overshooting scenarios becomes the highest among the scenario considered here. This is regarded as the mechanism by which the ECS correlates with the scenario dependence of the TCRE. Indeed, Tachiiri et al. (2015) also showed a positive relationship between the ECS and TCRE, and this proposed mechanism probably explains their observation that stabilization of the $\mathrm{pCO}_{2}$ resulted in enhanced TCRE increases during the $\mathrm{pCO}_{2}$-increasing period for high-TCRE models and TCRE decreases for low-TCRE models. In brief, the results presented herein can explain why the use of a high ECS model (MIROC-ESM, 4.7K; Andrews et al. 2012) revealed an increase in the TCREs under overshooting scenarios (Tachiiri et al. 2019), whereas the relatively low climate sensitivity of the MIROC-ES2L model $(\mathrm{ECS}=2.7 \mathrm{~K}$; MacDougall et al. 2020) did not give that outcome.

For each scenario, the deviations (root-mean-square errors) of the TCREs from that of the $I-1 \%$ scenario are related to the ECS, $\mathrm{CO}_{2}$-carbon cycle feedback $(\beta)$, and climate-carbon cycle feedback $(\gamma)$ in Figure S2, while the correlations between the TCRE and the $\beta$ and $\gamma$ are indicated by the scatter plots in Figures S4 and S5, respectively. Thus, a larger $\beta$ is seen to result in a relatively small scenario dependence for the TCRE, as does a large (small negative) $\gamma$ value (Figure S2). Here, it is worth noting that the members with $\gamma<-300 \mathrm{PgC} / \mathrm{K}$ have small ECS, thus resulting in small weights and a small temperature rise.

Care should be exercised on the limitations of EMICs or differences in the behaviors between EMICs and full ESMs. Tokarska et al. (2016) found that the TCRE was stable for the Representative Concentration Pathway 8.5 scenario, but tended to decrease for EMICs, when the cumulative carbon emissions were large. In addition, MacDougall et al. (2020) identified a positive relationship between the ZEC and the ECS in ESMs, but this tendency disappeared when EMICs were added. Moreover, although the correlation between the ECS and ZEC was small, the same study showed a clear positive relationship between these values when different ECS versions of the same EMICs were compared, thus demonstrating that the use of a single-model ensemble 
(with varying parameters) can provide different results from those of a multi-model study.

\subsection{Implications for carbon budget estimation}

The values of the weighted $1^{\text {st }}-99^{\text {th }}$ TCRE percentiles for each scenario are plotted in Fig. 4. Thus, for the ensemble members of the lowest TCRE values, the scenario dependence of the TCRE is small. Among the $33^{\text {rd }}$, $50^{\text {th }}$, and $67^{\text {th }}$ percentiles, which present the remaining carbon budget in SR1.5 (Rogelj et al. 2018), the $33^{\text {rd }}$ percentile is relatively stable except for a slight decrease in the $I-4 \%$ scenario. For the $50^{\text {th }}$ and $67^{\text {th }}$ percentiles, the TCRE is slightly increased under $I-0.25 \%$ (by $8 \%$ and $13 \%$, respectively), while $12 \%$ and $20 \%$ increases are observed under the $D-1 \%$ scenario. For higher percentiles, the scenario dependence of the TCRE is significant, with a tendency toward low values under rapidly increasing $\mathrm{pCO}_{2}$ scenarios, high values under slowly increasing $\mathrm{pCO}_{2}$ scenarios, and even higher values under the decline-after-a-peak ( $D-1 \%)$ scenario. In this experiment, the 50th percentile in the dataset corresponds to the 1.6 $\mathrm{K} / 1000 \mathrm{GtC}$ for the $I-1 \%$ scenario. The $95 \%$ ranges $(2.5-$ 97.5 percentiles) are $0.9-1.6,1.0-2.0,1.0-2.3,1.0-2.6$, $0.9-3.0$, and $0.9-3.3 \mathrm{~K} / \mathrm{TtC}$ for the $I-4 \%, I-2 \%, I-1 \%, I-$ $0.5 \%, I-0.25 \%$, and $D-1 \%$ scenarios, respectively. Although the sample size is small, a linear regression is attempted in Figure S6 in order to estimate the TCRE using the ECS and the rate of increase in the $\mathrm{pCO}_{2}$. This enabled the derivation of Eq. (5):

$$
\begin{aligned}
\mathrm{TCRE}[\mathrm{K} / \mathrm{TtC}] & =(-0.091 \ln (I)+0.26) * \mathrm{ECS}[\mathrm{K}] \\
& +\max (0, \min (0.77,0.22 * \ln (I)+0.76))
\end{aligned}
$$

where $I$ is the rate of increase in $\mathrm{pCO}_{2}$ [ppa].

The remaining carbon budget calculated from the TCRE for at the $33^{\text {rd }}, 50^{\text {th }}$, and $67^{\text {th }}$ percentile of the $I-1 \%, I-$ $0.5 \%$, and $I-0.25 \%$ scenarios, along with the ratio of the

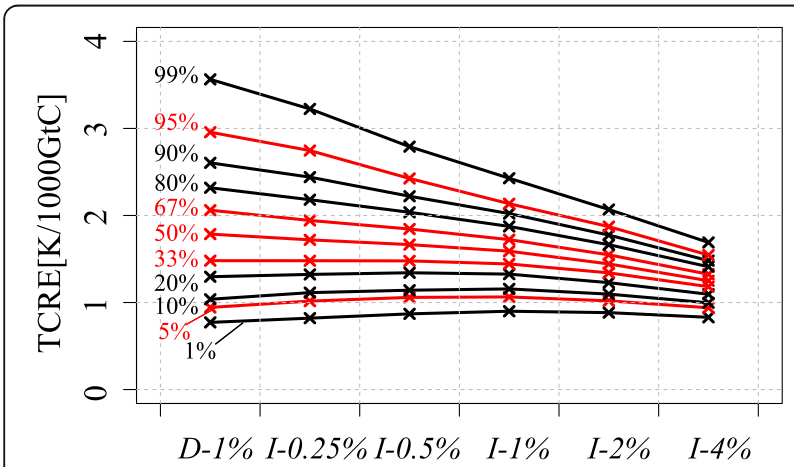

Fig. 4 Weighted values of the $1^{\text {st }}-99^{\text {th }}$ percentiles of the TCRE under each scenario. D-1\% scenario starts from a non-equilibrium state remaining carbon budget to that of the $I-1 \%$ at the same percentile, are presented in Table 4. The two remaining carbon budget values quoted for each scenario are those obtained before (left) and after (right) subtracting the estimated contribution of unpresented Earth system feedback $\left(100 \mathrm{GtCO}_{2}=27.3 \mathrm{GtC}\right.$; Rogelj et al. 2018). The $I-2 \%$ and $I-4 \%$ scenarios are not included because they are too fast for practical carbon budget estimation for temperature targets such as $1.5^{\circ} \mathrm{C}$ and $2{ }^{\circ} \mathrm{C}$. Meanwhile, the $D-1 \%$ scenario is excluded because Eq. (1) is not applicable to it (Rogelj et al. 2019). Here, the method of Tachiiri et al. (2019) was used to estimate the remaining carbon budget for the $1.5{ }^{\circ} \mathrm{C}$ target, i.e., using $T_{\text {lim }}-T_{\text {hist }}=0.53{ }^{\circ} \mathrm{C}$ in Eq. (1), assuming that the non- $\mathrm{CO}_{2}$ greenhouse gas contribution was 30\%, and that the 2011-2017 emissions were 79.4 PgC. The $T_{\mathrm{ZEC}}$ was expected to be scenario dependent but since only one scenario was assessed in this study, its value was assumed to be zero, following MacDougall et al. (2020). In this study, for the $I-1 \%$ scenario, the ZEC is found to be $0.07,0.11$, and $0.15^{\circ} \mathrm{C}$ for the $33^{\text {rd }}$, $50^{\text {th }}$, and $67^{\text {th }}$ percentile, respectively. Due to the scenario dependence of the TCRE, the remaining carbon budget could be reduced by $18 \%$ and $22 \%$ before and after subtracting the estimated contribution of unpresented Earth system feedback for the most extreme case (i.e., the $67^{\text {th }}$ percentile $I-0.25 \%$ scenario).

The ratio of the TCREs under the $D-1 \%$ and $I-1 \%$ scenarios is used as an indicator of the scenario dependence of the TCRE, and its relationship to the ZEC at the peak temperature is plotted in Fig. 5. Similar plots at 25 and 50 years after starting the zero-emission period are presented in Figure S7. In each case, a positive relationship between the ZEC and the scenario dependence of the TCRE can be observed. This is expected because the warming in the zero-emission period is an indicator of scenario dependence in terms of the temperature and the TCRE, as shown in Figure S8. Note that the ratio of the TCRE under the $D-1 \%$ and $I-1 \%$ scenarios is used in this analysis because the extreme scenario of $D-1 \%$ generates a large spread in TCRE.

Although the ZEC was considered in Eq. (1), the TCRE was assumed constant (having no scenario dependence). Nevertheless, as shown in Fig. 5, a non-zero ZEC is associated with the scenario dependence of the TCRE. Thus, for cases with no scenario dependence for the TCRE, and no ZEC, the ZEC term can be omitted from Eq. (1) and carbon budget estimation becomes relatively trivial. However, when a ZEC and scenario dependence of the TCRE occur, inclusion of the ZEC term may be insufficient. It is necessary to consider what specific scenario was used to estimate the TCRE and, if the scenario is significantly different, the TCRE value must be adjusted. This is particularly important when the ECS is large.

The pathways for maintaining the $2{ }^{\circ} \mathrm{C}$ target were previously analyzed with a realistic magnitude of overshoot by 
Table 4 Remaining carbon budget (RCB) for the $1.5{ }^{\circ} \mathrm{C}$ target based on the TCREs for the $1-1 \%, 1-0.5 \%$, and $1-0.25 \%$ scenarios

\begin{tabular}{|c|c|c|c|c|}
\hline Scenario & & $33^{\text {rd }}$ percentile & $50^{\text {th }}$ percentile & $67^{\text {th }}$ percentile \\
\hline \multirow[t]{3}{*}{$1-1 \%$} & TCRE (K/TtC) & 1.44 & 1.59 & 1.72 \\
\hline & $\mathrm{RCB}$ & $178 / 151$ & $154 / 127$ & 136/109 \\
\hline & Relative to $1-1 \%$ & $1.00 / 1.00$ & $1.00 / 1.00$ & $1.00 / 1.00$ \\
\hline \multirow[t]{3}{*}{$1-0.5 \%$} & TCRE (K/TtC) & 1.48 & 1.67 & 1.84 \\
\hline & $\mathrm{RCB}$ & $171 / 144$ & $143 / 115$ & $122 / 95$ \\
\hline & Relative to $1-1 \%$ & $0.961 / 0.954$ & $0.927 / 0.912$ & $0.897 / 0.871$ \\
\hline \multirow[t]{3}{*}{$1-0.25 \%$} & TCRE (K/TtC) & 1.48 & 1.72 & 1.94 \\
\hline & $\mathrm{RCB}$ & $171 / 144$ & $136 / 109$ & $112 / 85$ \\
\hline & Relative to $1-1 \%$ & $0.961 / 0.954$ & $0.885 / 0.861$ & $0.821 / 0.776$ \\
\hline
\end{tabular}

Tokarska et al. (2019) to indicate identical cumulative $\mathrm{CO}_{2}$ emissions for both overshooting and non-overshooting pathways. They concluded that no corrections are needed for ambitious mitigation scenarios with the low levels of overshoot presented in SR1.5. The present study confirms their output (which is available at http://data.iac.ethz.ch/ Tokarska_et_al_2019_Overshoot_UVicESCM/, and was accessed on May 8, 2020) and found that the TCRE is slightly larger in the negative emission period, moderate in the slow emission period, and small in the rapid emission period. More importantly, however, the differences in the TCREs between the scenarios and periods were small $(<$ $5 \%$ ), which is presumed to lead to almost identical cumulative carbon emissions for both pathways. For the experiments described herein, the relationship between the ECS and the scenario dependence of the cumulative carbon emission for the $1.5^{\circ} \mathrm{C}$ target shown in Fig. 6 indicates that this outcome only occurs when the ECS is low. By contrast, when the ECS is high, an overshooting scenario could generate a significant reduction in the carbon budget. Thus,

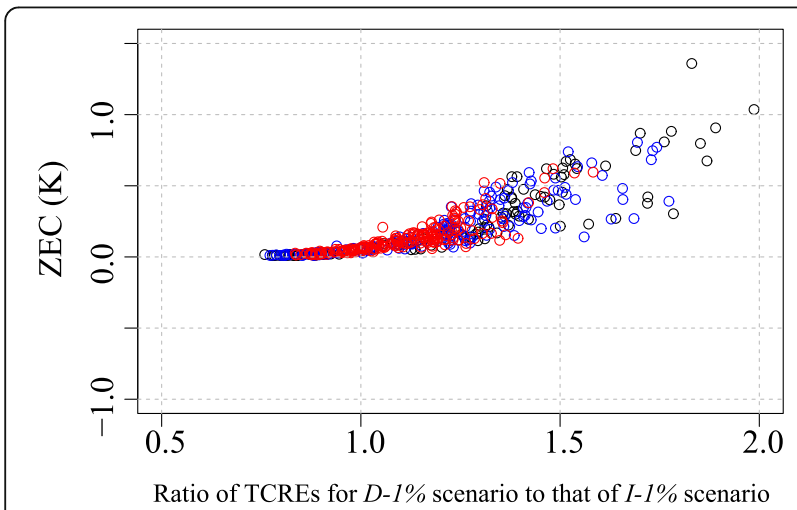

Fig. 5 The relationship between the ZEC and the scenario dependence of the TCRE. The ZEC is presented at the peak temperature after the cessation of $\mathrm{CO}_{2}$ emissions. Ratio of TCREs for D-1\% (starting from a non-equilibrium state) to that of $1-1 \%$ scenarios is used as an indicator of the scenario dependence. The red, blue, and black circles indicate members with weights of $>0.5$, $0.1-0.5$, and $<0.1$, respectively more research is needed to determine whether a correction is required in carbon budget estimation methods for overshooting pathways.

\section{Conclusions}

Considering the importance of the TCRE in estimating the remaining carbon budget, the magnitude of scenario dependence and its relation to physical and biogeochemical parameters were investigated via ensemble experiments using an EMIC. The results indicated that, on average, the TCRE decreases in scenarios with a rapid rate of $\mathrm{CO}_{2}$ increase, and increases in scenarios with a slow rate of $\mathrm{CO}_{2}$ increase. Moreover, the declining part of an overshooting scenario was shown to generate an even larger TCRE than the slow $\mathrm{CO}_{2}$ increase scenario.

Among the parameters considered, the ECS displayed by far the strongest correlation with the scenario

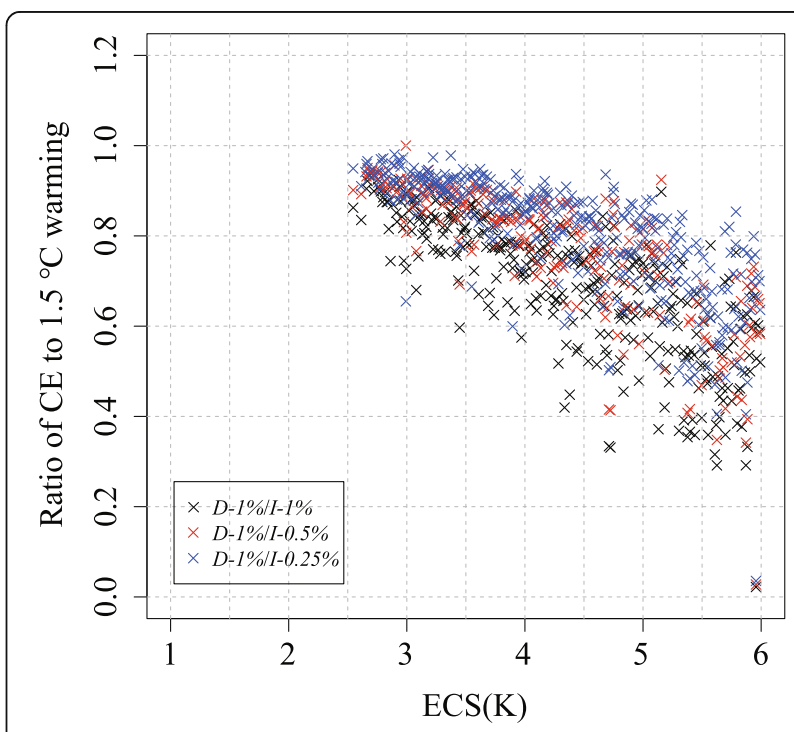

Fig. 6 Relationship between the ECS and the scenario dependence of the cumulative carbon emission for the $1.5^{\circ} \mathrm{C}$ target: $D-1 \%$ to $1-1 \%$ (black), D-1\% to $1-0.5 \%$ (red), and D-1\% to $1-0.25 \%$ (blue). Members with a low ECS (approximately $<2.5 \mathrm{~K}$ ) do not reach the $1.5^{\circ} \mathrm{C}$ warming level from the initial state 
dependence of the TCRE. This is attributed to the longer response time in the high ECS model and can explain why the use of a high ECS model (MIROC-ESM, 4.7 K; Andrews et al. 2012) revealed an increase in the TCRE under overshooting scenarios (Tachiiri et al. 2019), whereas this was not observed when using the MIROC-ES2L (ECS = $2.7 \mathrm{~K})$. Here, when the ECS was high, the ECS correlation was reduced for fast scenarios, and the correlations of the biogeochemical parameters were strengthened compared to those in slow scenarios.

In the slower scenarios, the TCRE increase was found to be more significant when the ECS was high. As such, the remaining carbon budget for the $1.5{ }^{\circ} \mathrm{C}$ target could be significantly reduced in the slow $\mathrm{pCO}_{2}$ scenarios. For example, the $67^{\text {th }}$ percentile values for the $I-0.25 \%$ scenario before and after subtracting the estimated contribution of the unpresented Earth system feedback were reduced by $18 \%$ or $22 \%$ relative to the case using the value for the $I-1 \%$ scenario, respectively, thus indicating that the scenario dependence of the TCRE could cause non-negligible changes in the remaining carbon budget. For an overshooting scenario (i.e., $I-1 \%+D-1 \%$ ), the cumulative carbon emission to $1.5{ }^{\circ} \mathrm{C}$ warming was found to be reduced compared to the slow increasing (e.g., I$0.25 \%)$ scenarios for high ECS cases. In the present study, the scenario dependence of the realized warming fraction demonstrated that the ZEC is also likely to be scenario dependent, and could therefore be included in calculating the carbon budget. However, the incorporation of the ZEC term into the carbon budget estimation remains as future work because the specifics are beyond the scope of the present study.

The quasi-constant TCRE concept is both scientifically interesting and practically helpful, and there are many other uncertainties in carbon budget estimation (e.g., GMST observation). However, an investigation of the subtle differences in the TCRE is meaningful for both attaining a deeper understanding of the climate-carbon cycle system and for more practical carbon budget estimation.

Notably, the present study was conducted using a single EMIC. The difference in the behaviors between ESMs and EMICs is sometimes non-negligible and the results of a single-model ensemble can differ from those of a multi-model ensemble. The methods used to simplify the EMIC and select the range of parameter variation could also affect the results. However, considering the significance of the impact, and the tendency for Coupled Model Inter-comparison Project Phase6 (CMIP6) models to have larger ECS values than previous versions (Zelinka et al. 2020; Meehl et al. 2020), an investigation into the scenario dependency of the TCRE in state-of-the-art ESMs could be very important future work.

\section{Supplementary Information}

The online version contains supplementary material available at https://doi. org/10.1186/s40645-020-00392-6.

Additional file 1: Figure S1. Weights used for the parameters: (a) ECS (b) maximum photosynthetic rate, and (c) specific leaf area (see Table 1). Figure S2. The weighted relationships between the deviations (rootmean-square errors) of the ratios of the TCRE to that of the $1-1 \%$ scenario and (a) the ECS, (b) $\beta$, and (c) $\gamma$. D-1\% scenario starts from a nonequilibrium state. "All" indicates the total (root-mean-square) of all scenarios, and "Slow" indicates that for $D-1 \%, 1-0.25 \%$ and $1-0.5 \%$ scenarios. Figure S3. The ECS dependence of $(a, c)$ the temperature, $(b$, d) the cumulative carbon emissions for (a, b) $2 \times \mathrm{CO}_{2}$, (c, d) $1.5 \times \mathrm{CO}_{2}$, (e) transient warming at the $2 \times \mathrm{CO}_{2}$ level, and (f) the realized warming fraction (i.e., the ratio of the transient warming at the $2 \times \mathrm{CO}_{2}$ level to the ECS). D-1\% scenario starts from a non-equilibrium state. Figure S4. The correlation between the $\mathrm{CO}_{2}$-carbon cycle feedback ( $\beta$ ) and (a) the TCRE under the $1-1 \%$ scenario and $(b-f)$ the relative change in the TCRE from that under $1-1 \%$ for (b) the $D-1 \%$ (starting from a non-equilibrium state), (c) the $1-0.25 \%$, (d) the $1-0.5 \%$, (e) the $1-2 \%$, and (f) the $1-4 \%$ scenarios. The red, blue, and black circles indicate members with weights of $>0.5,0.1-$ 0.5 , and $<0.1$, respectively. Figure $\mathbf{S 5}$. Correlations between the climatecarbon cycle feedback $(\gamma)$ and (a) the TCRE under the $1-1 \%$ scenario, and (b-f) the relative change in the TCRE from that of the $1-1 \%$ for $(b)$ the $D$ $1 \%$ (starting from a non-equilibrium state), (c) the $1-0.25 \%$, (d) the $1-0.5 \%$, (e) the $1-2 \%$, and ( $f$ ) the $1-4 \%$ scenarios. The red, blue, and black circles indicate members with weights of $>0.5,0.1-0.5$, and $<0.1$, respectively. Figure S6. The slopes (a) and intercepts (b) of the linear regressions of the TCRE for the ECS under each scenario plotted against the rate of increase in $\mathrm{pCO}_{2}$ for each scenario. The $D-1 \%$ scenario, starting from a nonequilibrium state, is indicated by the orange circle but is excluded from the regression. Figure S7. The relationship between (a) the ZEC25 and (b) the ZEC50 and the scenario dependence of the TCRE. Ratio of TCREs for $D-1 \%$ (starting from a non-equilibrium state) to that of $1-1 \%$ scenarios is used as an indicator of the scenario dependence. The red, blue, and black circles indicate members with weights of $>0.5,0.1-0.5$, and $<0.1$, respectively. Figure S8. Schematic relationship between the ZEC and the scenario dependence of the TCRE: (a) initial scenario, (b) same scenario followed by a 70-year ZEC period.

\section{Abbreviations}

AR5: The Fifth Assessment Report (of IPCC); ECS: Equilibrium climate sensitivity; EMIC: Earth system model of intermediate complexity; ESM: Earth system model; GMSAT: Global mean surface air temperature;

IPCC: Intergovernmental Panel on Climate Change; $\mathrm{PCO}_{2}$ : Atmospheric $\mathrm{CO}_{2}$ concentration; SR1.5: Special Report on Global Warming of $1.5^{\circ} \mathrm{C}$ (of IPCC);

TAB: Threshold avoidance budget; TCRE: Transient climate response to cumulative carbon emissions; TEB: Threshold exceedance budget; ZECMIP: Zero-emission commitment model inter-comparison project; $\beta$ : Magnitude of the $\mathrm{CO}_{2}$-carbon cycle feedback; $\gamma$ : Magnitude of the climate-carbon cycle feedback

\section{Acknowledgements}

The author would like to thank Dr. Hiroaki Tatebe of the Japan Agency for Marine-Earth Science and Technology (JAMSTEC) for his helpful comments on uncertainty in ocean physics parameters and Dr. Akira Oka of the University of Tokyo for his additional helpful comments on the same topic and on the treatment of wind speed. I would also like to thank Dr. Junichi Tsutsui of Central Research Institute of Electric Power Industry for his helpful comments on the relationship between transient climate response and equilibrium climate sensitivity. This work was supported by TOUGOU, the "Integrated Research Program for Advancing Climate Models" (Grant Number JPMXD0717935715) of the Ministry of Education, Culture, Sports, Science and Technology of Japan. The experiments were carried out using Data Analyzer System of the Japan Agency for Marine-Earth Science and Technology.

\section{Author's contributions}

KT designed and carried out the experiments, analyzed the results, and prepared the manuscript. The author read and approved the final manuscript. 


\section{Author information}

$\mathrm{K} T$ is the leader of the Earth System Model Development and Application Group at the Research Center for Environmental Modeling and Application of the Japan Agency for Marine-Earth Science and Technology.

\section{Funding}

This work was supported by TOUGOU, the "Integrated Research Program for Advancing Climate Models" of the Ministry of Education, Culture, Sports, Science and Technology of Japan. (Grant Number JPMXD0717935715).

\section{Availability of data and materials}

The datasets used and/or analyzed during the current study are available from the corresponding author on reasonable request.

\section{Competing interests}

The authors declare that they have no competing interest.

\section{Received: 31 December 2019 Accepted: 10 November 2020} Published online: 09 December 2020

\section{References}

Andrews T, Gregory JM, Webb MJ, Taylor KE (2012) Forcing, feedbacks and climate sensitivity in CMIP5 coupled atmosphere-ocean climate models. Geophys Res Lett 39:L09712. https://doi.org/10.1029/2012GL051607

Arora VK, Katavouta A, Williams RG, Jones CD, Brovkin V, Friedlingstein P, Schwinger J, Bopp L, Boucher O, Cadule P, Chamberlain MA, Christian JR, Delire C, Fisher RA, Hajima T, Ilyina T, Joetzjer E, Kawamiya M, Koven C, Krasting J, Law RM, Lawrence DM, Lenton A, Lindsay K, Pongratz J, Raddatz T, Séférian R, Tachiiri K, Tjiputra JF, Wiltshire A, Wu T, Ziehn T (2020) Carbonconcentration and carbon-climate feedbacks in CMIP6 models, and their comparison to CMIP5 models. Biogeosciences 17:4173-4222. https://doi.org/ 10.5194/bg-17-4173-2020

Bindoff NL, Stott PA, AchutaRao KM, Allen MR, Gillett N, Gutzler D, Hansingo K, Hegerl G, Hu Y, Jain S, Mokhov II, Overland J, Perlwitz J, Sebbari R, Zhang X (2013) Detection and attribution of climate change: from global to regional. In: Climate Change 2013: The Physical Science Basis. Contribution of Working Group I to the Fifth Assessment Report of the Intergovernmental Panel on Climate Change [Stocker TF, Qin D, Plattner G-K, Tignor M, Allen SK, Boschung J, Nauels A, Xia Y, Bex V, Midgley PM (eds.)]. Cambridge University Press, Cambridge, United Kingdom and New York, NY, USA.

Bolstad PV, Mitchell KA, Vose JM (1999) Foliar temperature-respiration functions for broad-leaved tree species in the southern Appalachians. Tree Physiol 19: $871-878$

Ciais P, Sabine C, Bala G, Bopp L, Brovkin V, Canadell J, Chhabra A, DeFries R, Galloway J, Heimann M, Jones C, Le Quéré C, Myneni RB, Piao S and Thornton P (2013) Carbon and other biogeochemical cycles. In: Climate Change 2013: The Physical Science Basis. Contribution of Working Group I to the Fifth Assessment Report of the Intergovernmental Panel on Climate Change [Stocker TF, Qin D, Plattner G-K, Tignor M, Allen SK, Boschung J, Nauels A, Xia Y, Bex V, Midgley PM (eds.)]. Cambridge University Press, Cambridge, United Kingdom and New York, NY, USA

Collins M, Brierley CM, MacVean M, Booth BBB, Harris GR (2007) The sensitivity of the rate of transient climate change to ocean physics perturbations. J Clim 20:2315-2320

Collins MR, Knutti R, Arblaster J, Dufresne J-L, Fichefet T, Friedlingstein P, Gao X, Gutowski WJ, Johns T, Krinner G, Shongwe M, Tebaldi C, Weaver AJ, Wehner M (2013) Long-term climate change: projections, commitments and irreversibility. In: Stocker T F et al. (ed) Climate Change 2013: The Physical Science Basis. Contribution of Working Group I to the Fifth Assessment Report of the Intergovernmental Panel on Climate Change, Cambridge University Press, Cambridge, United Kingdom and New York, NY, USA.

Copernicus Climate Change Service (C3S) (2017) ERA5: Fifth generation of ECMW $\mathrm{F}$ atmospheric reanalyses of the global climate. Copernicus climate change service climate data store (CDS), date of access. https://cds.climate. copernicus.eu/cdsapp\#!/home doi:https://doi.org/10.24381/cds.f17050d7

Denman KL, Brasseur G, Chidthaisong A, Ciais P, Cox PM, Dickinson RE, Hauglustaine D, C. Heinze, Holland E, Jacob D, Lohmann U, Ramachandran S, da Silva Dias PL, Wofsy SC, Zhang X (2007) Couplings between changes in the climate system and biogeochemistry. In: Climate Change 2007: The Physical Science Basis. Contribution of Working Group I to the Fourth Assessment Report of the Intergovernmental Panel on Climate Change
[Solomon S, Qin D, Manning M, Chen Z, Marquis M, Averyt KB, Tignor M, Miller HL (eds.)]. Cambridge University Press, Cambridge, United Kingdom and New York, NY, USA.

Eby M, Weaver AJ, Alexander K, Zickfeld K, Abe-Ouchi A, Cimatoribus AA Crespin E, Drijfhout SS, Edwards NR, Eliseev AV, Feulner G, Fichefet T, Forest CE, Goosse H, Holden PB, Joos F, Kawamiya M, Kicklighter D, Kienert H, Matsumoto K, Mokhov II, Monier E, Olsen SM, Pedersen JOP, Perrette M, Philippon-Berthier G, Ridgwell A, Schlosser A, Schneider von Deimling T, Shaffer G, Smith RS, Spahni R, Sokolov AP, Steinacher M, Tachiiri K, Tokos K, Yoshimori M, Zeng N, Zhao F (2013) Historical and idealized climate model experiments: an EMIC intercomparison. Clim Past 9:1111-1140. https://doi.org/10.5194/cp-9-1111-2013 (published on 5/16)

Friedlingstein P, Cox P, Betts R, Bopp L, Von Bloh W, Brovkin V, Cadule P, Doney S, Eby M, Fung I, Bala G, John J, Jones C, Joos F, Kato T, Kawamiya M, Knorr W, Lindsay K, Matthews H, Raddatz T, Rayner P, Reick C, Roeckner E, Schnitzler K, Schnur R, Strassmann K, Weaver A, Yoshikawa C, Zeng N (2006) Climate-carbon cycle feedback analysis: results from the C4MIP model intercomparison. J Clim 19:3337-3353. https://doi.org/10.1175/jcli3800.1

Gent PR, McWilliams JC (1990) Isopycnal mixing in ocean circulation models. J Phys Oceanogr 20:150-155

Gillett NP, Arora VK, Matthews D, Allen MR (2013) Constraining the ratio of global warming to cumulative CO2emissions using CMIP5 simulations. J Clim 26: 6844-6858. https://doi.org/10.1175/JCLI-D-12-00476.1

Gong H, Gao J (2019) Soil and climatic drivers of plant SLA (specific leaf area). Global ecology and conservation 20:e00696. https://doi.org/10.1016/j.gecco. 2019.e00696

Gregory JM, Jones CD, Cadule P, Friedlingstein P (2009) Quantifying carbon cycle feedbacks. J Clim 22:5232-5250

Hajima T, Kato E, Kawamiya M, Liddicoat S, Lindsay K, Reick C, Roelandt C, Segschneider J, Tjiputra J (2012) 21st century compatible CO2 emissions and airborne fraction simulated by CMIP5 earth system models under 4 representative concentration pathways. J Clim 26:4398-4413. https://doi.org/ 10.1175/JCLI-D-12-00554.1

Hajima T, Watanabe M, Yamamoto A, Tatebe H, Noguchi M, Abe M, Ohgaito R, Ito A, Yamazaki D, Okajima H Ito A, Takata K, Ogochi K, Watanabe S, Kawamiya M (2020) Description of the MIROC-ES2L Earth system model and evaluation of its climate-biogeochemical processes and feedbacks. Geosci Model Dev https://doi.org/10.5194/gmd-2019-275

Hasumi H, Suginohara N (1999) Atlantic deep circulation controlled by heating in the Southern Ocean. Geophys Res Lett 26:1873-1876

Huber M, Zanna L (2017) Drivers of uncer tainty in simulated ocean circulation and heat uptake. Geophys Res Lett 44:1402-1413

Ito A, Oikawa T (2002) A simulation model of the carbon cycle in land ecosystems (Sim-CYCLE): a description based on drymatter production theory and plot-scale validation. Ecol Model 151:143-176

K-1 Model Developers (2004) K-1 coupled GCM (MIROC) Description, edited by Hasumi H and Emori S, K-1 Technical Report 1, 34pp. Cent For Clim Syst Res, Univ. of Tokyo, Kashiwa, Japan

Kattge J, Diaz S, Lavorel S, Prentice C, Leadley P, Boenisch G, Garnier E, Westoby M, Reich PB, Wright IJ, Cornelissen JHC, Violle C, Harrison SP, van Bodegom PM, Reichstein M, Enquist BJ, Soudzilovskaia NA, Ackerly DD, Anand M, Atkin O, Bahn M, Baker TR, Baldocchi D, Bekker R, Blanco CC et al. (2011) TRY-a global database of plant traits. Glob Chang Biol 17:2905-2935. https://doi. org/10.1111/j.1365-2486.2011.02451.x

Krasting JP, Dunne JP, Shevliakova E, Stouffer RJ (2014) Trajectory sensitivity of the transient climate response to cumulative carbon emissions. Geophys Res Lett 41:2520-2527. https://doi.org/10.1002/2013GL059141

MacDougall AH (2017) The oceanic origin of path-independent carbon budgets. Sci Rep 7:10373

MacDougall AH, Frölicher TL, Jones CD, Rogelj J, Matthews HD, Zickfeld K, Arora VK, Barrett NJ, Brovkin V, Burger FA, Eby M, Eliseev AV, Hajima T, Holden PB, Jeltsch-Thömmes A, Koven C, Menviel L, Michou M, Mokhov II, Oka A, Schwinger J, Séférian R, Shaffer G, Sokolov A, Tachiiri K, Tjiputra J, Wiltshire A Ziehn T (2020) Is there warming in the pipeline? A multi-model analysis of the zero emission commitment from CO2. Biogeosci Discuss. https://doi.org/ 10.5194/bg-2019-492

Meehl GA, Senior CA, Eyring V, Flato G, Lamarque J-F, Stouffer RJ, Taylor KE Schlund M (2020) Context for interpreting equilibrium climate sensitivity and transient climate response from the CMIP6 earth system models. Science Advances 6:eaba1981. https://doi.org/10.1126/sciadv.aba1981 
Melet A, Legg S, Hallberg R (2016) Climatic impacts of parameterized local and remote tidal mixing. J Clim 29:3473-3500. https://doi.org/10.1175/JCLI-D-150153.1

Millar RJ, Otto A, Forster PM, Lowe JA, Ingram WJ, Allen MR (2015) Model structure in observational constraints on transient climate response. Clim Chang 131:199-211

Oka A, Tajika E, Abe-Ouchi A, Kubota K (2011) Role of ocean in controlling atmospheric $\mathrm{CO} 2$ concentration in the course of global glaciations. Clim Dynam 37:1755-1770

Oort AH (1983) Global atmospheric circulation statistics 1958-1973. NOAA Prof Pap 14:180

Peterson AG, Ball JT, Luo YQ, Field CB, Reich PB, Curtis PS, Griffin KL, Gunderson CA, Norby RJ, Tissue DT, Forstreuter M, Rey A, Vogel CS (1999) The photosynthesis leaf nitrogen relationship at ambient and elevated atmospheric carbon dioxide: a meta-analysis. Glob Chang Biol 5:331-346

Roach CJ, Balwada D, Speer K (2018) Global observations of horizontal mixing from Argo float and surface drifter trajectories. J Geophys Res Oceans 123: 4560-4575. https://doi.org/10.1029/2018JC013750

Rogelj J, Forster PM, Kriegler E, Smith C, Séférian R (2019) Estimating and tracking the remaining carbon budget for stringent climate targets. Nature 571:335. https://doi.org/10.1038/s41586-019-1368-z

Rogelj J, Schaeffer M, Friedlingstein P, Gillett NP, van Vuuren D, Riahi K, Allen MR, Knutti R (2016) Differences between carbon budget estimates unravelled. Nature Clim Change 6:245-252. https://doi.org/10.1038/nclimate2868

Rogelj J, Shindell D, Jiang K, Fifita S, Forster P, Ginzburg V, Handa C, Kheshgi H, Kobayashi S, Kriegler E, Mundaca L, Séférian R, Vilariño MV (2018) Mitigation pathways compatible with $1.5^{\circ} \mathrm{C}$ in the context of sustainable development. In: Masson-Delmotte, V., P. Zhai, H.-O. Pörtner, D. Roberts, J. Skea, P.R. Shukla, A. Pirani, W. Moufouma-Okia, C. Péan, R. Pidcock, S. Connors, J.B.R. Matthews, Y. Chen, X. Zhou, M.I. Gomis, E. Lonnoy, T. Maycock, M. Tignor, and T. Waterfield (eds.) Global Warming of $1.5^{\circ} \mathrm{C}$. An IPCC Special Report on the impacts of global warming of $1.5^{\circ} \mathrm{C}$ above pre-industrial levels and related global greenhouse gas emission pathways, in the context of strengthening the global response to the threat of climate change, sustainable development, and efforts to eradicate poverty.

Simmons HL, Jayne SR, St. Laurent LC, Weaver AJ (2004) Tidally driven mixing in a numerical model of the ocean general circulation. Ocean Modell 6:245-263

Tachiiri K, Hajima T, Kawamiya M (2015) Increase of uncertainty in transient climate response to cumulative carbon emissions after stabilization of atmospheric CO2 concentration. Environ Res Lett 10:125018

Tachiiri K, Hajima T, Kawamiya M (2019) Increase of the transient climate response to cumulative carbon emissions with decreasing $\mathrm{CO} 2$ concentration scenarios. Environ Res Lett 14:124067. https://doi.org/10.1088/ 1748-9326/ab57d3

Tachiiri K, Hargreaves J, Annan J, Huntingford C, Kawamiya M (2013) Allowable carbon emissions for medium to high mitigation scenarios. TellusB 65:20586

Tachiiri K, Hargreaves JC, Annan JD, Oka A, Abe-Ouchi A, Kawamiya M (2010) Development of a system emulating the global carbon cycle in earth system models. Geosci Model Dev 3:365-376

Talley LD (2008) Freshwater transport estimates and the global overturning circulation: shallow, deep and throughflow components. Prog Oceanogr 78 257-303. https://doi.org/10.1016/j.pocean.2008.05.001

Tatebe H, Tanaka Y, Komuro Y, Hasumi H (2018) Impact of deep ocean mixing on the climatic mean state in the Southern Ocean. Scientific reports, no. 1, 14479 .

Tjoelker MG, Oleksyn J, Reich PB (2001) Modelling respiration of vegetation: evidence for a temperature-dependent Q10. Glob Change Biol 7:223-230

Tokarska KB, Gillett NP, Weaver AJ, Arora VK, Eby M (2016) The climate response to five trillion tonnes of carbon. Nat Clim Chang 6:851-855

Tokarska KB, Zickfeld K, Rogelj J (2019) Path independence of carbon budgets when meeting a stringent global mean temperature target after an overshoot. Earth's Future doi. https://doi.org/10.1029/2019EF001312

Tsutsui J (2017) Quantification of temperature response to CO2 forcing in atmosphere-ocean general circulation models. Clim Chang 140:287-305. https://doi.org/10.1007/s10584-016-1832-9

Tsutsui J (2020) Diagnosing transient response to CO2 forcing in coupled atmosphere-ocean model experiments using a climate model emulator. Geophys Res Lett 47:e2019GL085844. https://doi.org/10.1029/2019GL085844

Verbeeck H, Peylin P, Bacour C, Bonal D, Steppe K, Ciais P (2011) Seasonal patterns of $\mathrm{CO} 2$ fluxes in Amazon forests: fusion of eddy covariance data and the ORCHIDEE model. J Geophys Res 116:G02018. https://doi.org/10. 1029/2010JG001544

Visbeck M, Marshall J, Haine T, Spall M (1997) Specification of eddy transfer coefficients in coarse-resolution ocean circulation models. J Phys Oceanogr 27:381-402

Waterhouse AF, MacKinnon JA, Nash JD, Alford MH, Kunze E, Simmons HL, Polzin KL, St. Laurent LC, Sun OM, Pinkel R, Talley LD, Whalen CB, Huussen TN, Carter GS, Fer I, Waterman S, Naveira G, Alberto C, Sanford TB, Lee CM (2014) Global patterns of dia-pycnal mixing from measurements of the turbulent dissipation rate. J Phys Oceanogr 44:1854-1872. https://doi.org/10.1175/JPOD-13-0104.1

Weaver AJ, Sedáček J, Eby M, Alexander K, Crespin E, Fichefet T, PhilipponBerthier G, Joos F, Kawamiya K, Matsumoto K, Steinacher M, Tachiiri K, Tokos K, Yoshimori M, Zickfeld K (2012) Stability of the Atlantic meridional overturning circulation: a model intercomparison. Geophys Res Lett 39: L20709. https://doi.org/10.1029/2012GL053763

Zelinka MD, Myers TA, McCoy DT, Po-Chedley S, Caldwell PM, Ceppi P, Klein SA, Taylor KE (2020) Causes of higher climate sensitivity in CMIP6 models, Geophys Res Lett 47:e2019GL085782. doi:https://doi.org/10.1029/ 2019GL085782.

Zickfeld K, Eby M, Alexander K, Weaver AJ, Crespin E, Fichefet T, Goosse H, Philippon-Berthier G, Edwards NR, Holden PB, Eliseev AV, Mokhov II, Feulner $G$, Kienert $H$, Perrette $M$, Schneider von Deimling T, Forest $C E$, Friedlingstein $P$, Joos F, Spahni R, Steinacher M, Kawamiya M, Tachiiri K, Kicklighter D, Monier E, Schlosser A, Sokolov AP, Matsumoto K, Tokos K, Olsen SM, Pedersen JOP, Ridgwell A, Shaffer G, Yoshimori M, Zeng N, Zhao F (2013) Long-term climate change commitment and reversibility: an EMIC intercomparison. J Clim 26:5782-5809. https://doi.org/10.1175/JCLI-D-1200584.1

Zickfeld K, MacDougall AH, Matthews HD (2016) On the proportionality between global temperature change and cumulative $\mathrm{CO} 2$ emissions during periods of net negative CO2 emissions. Environ Res Lett 11:055006

\section{Publisher's Note}

Springer Nature remains neutral with regard to jurisdictional claims in published maps and institutional affiliations.

\section{Submit your manuscript to a SpringerOpen ${ }^{\circ}$ journal and benefit from:}

- Convenient online submission

- Rigorous peer review

- Open access: articles freely available online

- High visibility within the field

- Retaining the copyright to your article

Submit your next manuscript at $>$ springeropen.com 